\title{
Production of polyhydroxyalkanoates and enrichment of associated microbes in bioreactors fed with rice winery wastewater at various organic loading rates
}

Fang, Fang; Xu, Run Ze; Huang, Yan Qiu; Wang, Su Na; Zhang, Lu Lu; Dong, Jin Yun; Xie, Wen Ming; Chen, Xueming; Cao, Jia Shun

Published in:

Bioresource Technology

Link to article, DOI:

10.1016/j.biortech.2019.121978

Publication date:

2019

Document Version

Peer reviewed version

Link back to DTU Orbit

Citation $(A P A)$ :

Fang, F., Xu, R. Z., Huang, Y. Q., Wang, S. N., Zhang, L. L., Dong, J. Y., Xie, W. M., Chen, X., \& Cao, J. S. (2019). Production of polyhydroxyalkanoates and enrichment of associated microbes in bioreactors fed with rice winery wastewater at various organic loading rates. Bioresource Technology, 292, [121978].

https://doi.org/10.1016/j.biortech.2019.121978

\section{General rights}

Copyright and moral rights for the publications made accessible in the public portal are retained by the authors and/or other copyright owners and it is a condition of accessing publications that users recognise and abide by the legal requirements associated with these rights.

- Users may download and print one copy of any publication from the public portal for the purpose of private study or research.

- You may not further distribute the material or use it for any profit-making activity or commercial gain

- You may freely distribute the URL identifying the publication in the public portal 
See discussions, stats, and author profiles for this publication at: https://www.researchgate.net/publication/335086319

\section{Production of polyhydroxyalkanoates and enrichment of associated microbes in bioreactors fed with rice winery wastewater at various organic loading rates}

Article in Bioresource Technology · August 2019

DOI: 10.1016/.jbiortech.2019.121978

CITATIONS

3

9 authors, including:

Runze Xu

Hohai University

8 PUBLICATIONS 14 CITATIONS

SEE PROFILE

Some of the authors of this publication are also working on these related projects:

Project Deep learning for wastewater treatment View project

Project 10th IWA Symposium on Modelling and Integrated Assessment (Watermatex 2019) - Call for Abstracts View project

\section{READS}

158

Xueming Chen

Fuzhou University

62 PUBLICATIONS 435 CITATIONS

SEE PROFILE 


\section{Journal Pre-Proof}

Production of polyhydroxyalkanoates and enrichment of associated microbes in bioreactors fed with rice winery wastewater at various organic loading rates

Fang Fang, Run-Ze Xu, Yan-Qiu Huang, Su-Na Wang, Lu-Lu Zhang, Jin-Yun Dong, Wen-Ming Xie, Xueming Chen, Jia-Shun Cao

PII: S0960-8524(19)31208-8

DOI: https://doi.org/10.1016/j.biortech.2019.121978

Reference: BITE 121978

To appear in:

Bioresource Technology

Received Date:

23 July 2019

Revised Date:

6 August 2019

Accepted Date:

7 August 2019

Please cite this article as: Fang, F., Xu, R-Z., Huang, Y-Q., Wang, S-N., Zhang, L-L., Dong, J-Y., Xie, W-M., Chen, $\mathrm{X}$., Cao, J-S., Production of polyhydroxyalkanoates and enrichment of associated microbes in bioreactors fed with rice winery wastewater at various organic loading rates, Bioresource Technology (2019), doi: https://doi.org/ 10.1016/j.biortech.2019.121978

This is a PDF file of an article that has undergone enhancements after acceptance, such as the addition of a cover page and metadata, and formatting for readability, but it is not yet the definitive version of record. This version will undergo additional copyediting, typesetting and review before it is published in its final form, but we are providing this version to give early visibility of the article. Please note that, during the production process, errors may be discovered which could affect the content, and all legal disclaimers that apply to the journal pertain.

(C) 2019 Elsevier Ltd. All rights reserved. 
Production of polyhydroxyalkanoates and enrichment of associated microbes in

bioreactors fed with rice winery wastewater at various organic loading rates

Fang Fang ${ }^{1 *}$, Run-Ze Xu ${ }^{1}$, Yan-Qiu Huang ${ }^{1}$, Su-Na Wang ${ }^{1}$, Lu-Lu Zhang ${ }^{1}$, Jin-Yun Dong ${ }^{1}$, Wen-Ming Xie ${ }^{2}$, Xueming Chen ${ }^{3}$, Jia-Shun Cao ${ }^{1}$

${ }^{1}$ Key Laboratory of Integrated Regulation and Resource Development on Shallow Lakes, Ministry of Education, College of Environment, Hohai University, Nanjing 210098, China

${ }^{2}$ School of Environment, Nanjing Normal University, Nanjing, 210046, China

${ }^{3}$ Process and Systems Engineering Center (PROSYS), Department of Chemical and Biochemical Engineering, Technical University of Denmark, 2800 Kgs. Lyngby, Denmark

\section{* Corresponding author:}

Dr. Fang Fang, Fax: +86-25-83786701, E-mail: ffang65@hhu.edu.cn 


\section{Abstract}

This study aimed to explore the production of polyhydroxyalkanoates (PHA) and selection of PHA-accumulating microorganisms in bioreactors fed with rice winery wastewater at various organic loading rates (OLRs). The substrate utilization, sludge properties, PHA synthesis and microbial community structure of three sequencing batch reactors were monitored. The results show the highest PHA yield $(0.23 \mathrm{~g} / \mathrm{g})$ was achieved in one of the three reactors with an OLR of $2.4 \mathrm{~g} \mathrm{COD} / \mathrm{L} / \mathrm{d}$, in which Zoogloea was the most dominant PHA-accumulating microorganism. To quantify the PHA production and track the population changing profiles of the PHA-accumulating microorganisms in the long-term reactor operation, the Activated Sludge Model No. 3 was modified with two different heterotrophic microorganisms responding differently with the same substrate. The modeling results indicate that a moderate OLR $(>2.4$ $\mathrm{gCOD} / \mathrm{L} / \mathrm{d}$ ) was beneficial for PHA production. The results are useful for understanding the PHA production from industrial wastewaters and selection of PHAaccumulating microorganisms.

Keywords: polyhydroxyalkanoates (PHA); organic loading rate (OLR); rice winery wastewater; microbial enrichment; mathematical model 


\section{Introduction}

Due to the chemical resistance and thermostability, conventional plastics produced from fossil resources are widely used in daily life and industries at present, leading to a severe environmental pollution problem, which is called "white pollution"

(Colombo et al., 2016). To tackle this issue, great efforts have been made to search for biopolymers that are physiochemically similar to the conventional plastics but are environmentally friendly and sustainable (Rodriguez-Perez et al., 2018). Produced by prokaryotic microbes as intra-cellular storage materials, polyhydroxyalkanoates (PHA) are biopolymers with similar characteristics to the conventional plastics, but are biodegradable and biocompatible (Obruca et al., 2018). The excellent properties of PHA make them an ideal choice for medical and industrial applications (Pakalapati et al., 2018).

However, the currently limited use of PHA is the result of their relatively high production price, which is mainly dependent on the substrate sources, PHAaccumulating microorganisms, accumulation conditions and the subsequent recovery process. To lower the PHA production costs, many efforts have been made. For example, mixed microbial cultures (MMCs) have been used to replace pure cultures to produce PHA (Fradinho et al., 2013; Huang et al., 2017; Uma and Gandhimathi, 2019). Furthermore, low-cost agricultural and industrial waste feedstocks have been used as alternative substrates to reduce the PHA production costs (Burniol-Figols et 
al., 2018; Grazia et al., 2017).

The rice winery industry, one of the traditional industries in China, has not only created huge revenues but also generated plenty of pollutants. Large amounts of rice winery wastewater, which is mainly composed of sugars, ethanol, glycerol, esters and polyphenolic compounds, is produced in the brewing process (Mosse et al., 2011). If poorly disposed of, rice winery wastewater would cause a severe environmental pollution problem. Therefore, effective ways for rice winery wastewater treatment should be developed. Recently, several approaches for rice winery wastewater reutilization have been explored. For example, rice winery wastewater was converted to high-concentration industrial xanthan by specific microorganisms (Roncevic et al., 2017). It can also be used as a co-substrate with waste activated sludge to produce short-chain fatty acids via anaerobic fermentation (Luo et al., 2018). Since its main component is biodegradable organic matter, rice winery wastewater can also be used as the potential substrate for PHA production.

Aerobic dynamic feeding (ADF) is the most commonly used strategy for enriching PHA-accumulating microorganisms under the feast-famine regime (Coats et al., 2016; Li et al., 2011; Marang et al., 2016). In the feast period, PHA-accumulating microorganisms store external substrates as PHA, while the intracellular PHA is used by PHA-accumulating microorganisms as the carbon and energy source for cell growth and maintenance in the subsequent famine period. In this manner, PHAaccumulating microorganisms have a strong competitive advantage over other 
counterparts without the PHA-accumulating capacity (van Loosdrecht et al., 1997).

However, the enrichment of PHA-accumulating microorganisms is affected by many operational factors, among which organic loading rate (OLR) is recognized as a key one as OLR is tightly related to the substrate costs and significantly influences the metabolic process of microbial community (Oliveira et al., 2017). Moreover, OLR governs the feast-to-famine ratio $(\mathrm{F} / \mathrm{F})$, which affects the extent of selective pressure in microbial culture selection. In some previous studies the effect of OLR on the microbial culture selection process has been investigated. Campanari et al. (2014) found that the optimal PHA production occurred at an OLR of $4.70 \mathrm{gCOD} / \mathrm{L} / \mathrm{d}$ and that the highest PHA storage rate and yield reached $339 \pm 48 \mathrm{mgCOD} / \mathrm{gCOD} / \mathrm{h}$ and $0.56 \pm 0.05 \mathrm{gCOD} / \mathrm{gCOD}$, respectively. Farghaly et al. (2016) observed the maximum PHA content of $67.44 \pm 5.88 \%$ at an OLR of $1.5 \mathrm{gCOD} / \mathrm{L} / \mathrm{d}$ with dark fermented paperboard mill wastewater as the substrate. Wen et al. (2018) achieved the maximum PHA content of $33.4 \%$ at $2.5 \mathrm{~g} / \mathrm{L} \mathrm{NaCl}$ with waste fermentation leachate as the substrate. However, no information about the effects of OLR on the selection of PHAaccumulating microorganisms and PHA production from rice winery wastewater is available so far.

Furthermore, due to the complexity of operation conditions in PHA production process, many factors should be optimized for PHA production. However, at the present time, experiments have to be repeated to determine the optimal operation conditions, which is time-consuming and costly. Thus, mathematical models are 
proposed to describe PHA production processes and optimize operational parameters.

With the calibrated and validated mathematical models for PHA storage, the optimal operation conditions in PHA production process can be obtained. Microbial PHA formation as a complex biological process has been simulated by different mathematical models (Chen et al., 2016; Das and Grover, 2018; Elsayed et al., 2018; Li et al., 2018). However, mostly existing mathematical models for PHA production are based on batch experiments or short-term experiments. Moreover, long-term simulation of microbial selection process can provide useful information to optimize actual microbial selection process at the initial stage of PHA production by MMC.

Therefore, the objective of this study was to explore the enrichment of the PHAaccumulating microorganisms and production of PHA with rice winery wastewater as the substrate at various OLRs through combining experimental and mathematical modeling methods. The substrate utilization, sludge properties, and PHA synthesis at various OLRs were evaluated. Also, the microbial community was investigated by 16S rDNA gene high-throughput sequencing to further understand the effects of OLR on the PHA-accumulating microorganisms selection process. Finally, a modified mathematical model was established to simulate the substrate consumption, PHA production and long-term selection of PHA-accumulating microorganisms.

\section{Materials and Methods}




\subsection{Rice winery wastewater characterization and reactor long-term experimental}

setup

To enrich the PHA-accumulating microorganisms under the feast-famine regime, three 3-L sequencing batch reactors (SBRs, named as A, B and C) were operated with different OLRs $(1.2,2.4$ and $3.6 \mathrm{gCOD} / \mathrm{L} / \mathrm{d})$ in 6-h cycles, consisting of feeding (5 min), aeration (320 min), settling (15 min), withdrawal (5 min) and idle phase (15 min). Seeding sludge was collected from a municipal wastewater treatment plant in Nanjing City, China. Before inoculation, the sludge was washed twice by pure water and filtrated through the $0.6-\mathrm{mm}$ screen to remove particles. The initial sludge concentration in each SBR was about $3000 \mathrm{mg} / \mathrm{L}$. Supernatant of $1.5 \mathrm{~L}$ was discharged in every withdrawal period. Then, $1.5-\mathrm{L}$ diluted rice winery wastewater was fed in every feeding period. The hydraulic retention time (HRT) was kept at $12 \mathrm{~h}$. Air was supplied at the bottom of the SBRs by an air pump through gravel diffusers and controlled at $100 \mathrm{~L} / \mathrm{h}$ with dissolved oxygen (DO) concentration of $>2 \mathrm{mg} / \mathrm{L}$. The three reactors were operated at room temperature $\left(25-30^{\circ} \mathrm{C}\right)$. Sludge retention time (SRT) was kept at 10 days through wasting mixed liquor at the end of aeration periods. The raw rice winery wastewater was obtained from Shuanggou Rice Winery Plant in Huaiyin City, China. The concentrations of total chemical oxygen demand (TCOD), soluble chemical oxygen demand (SCOD), total nitrogen and total phosphorus in the raw rice winery wastewater were $170336 \pm 1080 \mathrm{mgCOD} / \mathrm{L}$, $150123 \pm 965 \mathrm{mgCOD} / \mathrm{L}, 2274 \pm 28 \mathrm{mgN} / \mathrm{L}$ and $872 \pm 34 \mathrm{mgP} / \mathrm{L}$, respectively. The 
initial $\mathrm{pH}$ of the raw rice winery wastewater was $3.4 \pm 0.2$. The raw wastewater was diluted at different ratios by deionized water and used as the influent of the three SBRs. The $\mathrm{pH}$ of diluted rice winery wastewater was adjusted to $7.0 \pm 0.2$ by adding $\mathrm{NaOH}(5 \mathrm{M})$.

\subsection{Batch experiment setup}

After 45-d reactor operation at various OLRs, batch experiment was conducted. The OLRs in the three batch experiments were controlled at 1.2, 2.4 and 3.6 $\mathrm{gCOD} / \mathrm{L} / \mathrm{d}$. The operation conditions, such as temperature, $\mathrm{DO}$, cycle time and the $\mathrm{pH}$ of feeding, were as same as those for the long-term experiment. The COD, total nitrogen $(\mathrm{TN})$, total phosphorus (TP) and PHA were monitored in the batch experiment process.

\subsection{Model-based evaluations}

The mathematical model applied in this study was modified based on the Activated Sludge Model No. 3 (ASM3) (Gujer et al., 1999). The modified ASM3 focuses on the aerobic storage process involving three dissolved model components and four particulate model components (Table 1). In this modified model, the microorganisms were divided into PHA-accumulating microorganism $\left(X_{P A B}\right)$ and nonPHA-accumulation microorganism $\left(X_{H}\right)$. Five component processes, including aerobic growth of active heterotrophic bacteria without PHA accumulation $\left(X_{H}\right)$ on external 
substrate, aerobic storage of PHA $\left(X_{P H A}\right)$ in active PHA accumulating bacteria $\left(X_{P A B}\right)$, aerobic growth of active PHA accumulating bacteria $\left(X_{P A B}\right)$ on $X_{P H A}$, aerobic decay of $X_{H}$ and $X_{P A B}$, were taken into consideration. In these processes, all substrates $\left(S_{S}\right)$ in rice winery wastewater were assumed to be biodegradable.

Sensitivity analysis was performed for all parameters used in this modified model with two key variables, $X_{P H A}$ and $S_{S}$. The modified model was first calibrated with data of substrate consumption and PHA accumulation in the batch experiment of SBR-B on Day 45. Some parameters were set as those reported by Gujer et al. (1999), while other parameters $\left(Y_{P H A}, Y_{P A B}, Y_{H, S}, \mu_{H, S}, \mu_{P A B}, q_{P H A}\right.$ and $\left.K_{P H A}\right)$ were estimated in this study as they significantly affect the PHA production and microbial selection process. The function of parameter estimation in AQUASIM V2.1 was conducted through minimizing the chi-squared criterion $\chi^{2}$ (weighted least squares) between the experimental and simulated results (Reichert et al., 1998). Afterwards, the modified ASM3 model was used to simulate the long-term PHA-accumulating microbial selection process. The initial inoculation conditions applied in the microbial selection experiment were used as the initial conditions of the modified model (Table 4). Then, the modified model was run to simulate the long-term microbial selection of PHAaccumulating microorganisms, and PHA production performance at various OLRs. The simulation results were compared with the experimental measurements.

\subsection{PHA extraction and quantification}


The mixed sludge samples of $10-\mathrm{mL}$ aliquot (one centrifuge tube) was collected from each SBR with 2 drops of sulfuric acid to stop all biological activity and then was centrifuged at $6000 \mathrm{rpm}$ and $4^{\circ} \mathrm{C}$ for $10 \mathrm{~min}$. The supernatant was discarded and $2.5 \mathrm{~mL}$ acetone was added into the centrifuge tube. After the sludge pellet was completely mixed with acetone, the sample was washed twice with deionized water and freeze dried by vacuum freeze dryer (Labconco, USA).

The quantity and composition of PHA were determined by a gas chromatography (GC, 7820A, Agilent Co., USA). 20-mg lyophilized sample was mixed with $2 \mathrm{~mL}$ chloroform, $2 \mathrm{~mL} \mathrm{10 \% (v/v)} \mathrm{sulfuric} \mathrm{acid} \mathrm{in} \mathrm{methanol} \mathrm{and} 0.2 \mathrm{~mL}(2 \mathrm{~g} / \mathrm{L})$ benzoic acid in methanol. Then, the solution was heated for $6 \mathrm{~h}$ at $100^{\circ} \mathrm{C}$ in a $5 \mathrm{~mL}$ Wheaton tube. After the sample cooled down, 1-mL deionized water was added. The solution was shaken violently and 1-L lower organic phase was collected for GC analysis. Following the procedure described by Wang et al. (2014), the GC analysis of PHA samples was performed on GC equipped with a ) $\mathrm{m} .32 \mathrm{~mm} .25 \mu \mathrm{m}$ HP-5 column. The concentrations of PHB and PHV were calibrated through standard curves with a solution made of a commercial co-polymer of PHB-PHV (95:5 w:w) (Sigma Co., USA) and benzoic acid as internal standard. The PHA content (\%) was calculated as PHA weight (g) divided by the cell dry weight (g) of GC samples. The yield of PHA was calculated as PHA weight $(\mathrm{g})$ divided by the consumed COD $(\mathrm{g})$ in the batch experiments. 


\subsection{Analytic methods}

The COD, $\mathrm{NH}_{4}{ }^{+}, \mathrm{TN}$ and $\mathrm{TP}$ in the influent and effluent were monitored every five days. The PHA samples were collected at the end of feast period and the end of the famine period every 5 days. Mixed liquid volatile suspended solids (MLVSS) and sludge volume index (SVI) were also measured every 5 days.

The DO concentration in three reactors was measured with a HQ30d DO electrode (HACH Inc., USA) while the $\mathrm{pH}$ was monitored with a $6010 \mathrm{M}$ pH electrode (JENCO, USA). COD, $\mathrm{NH}_{4}^{+}$, TN, TP, MLVSS and SVI were measured according to the Standard Methods (APHA., 2005). Simulations were done in AQUASIM V2.1 (Reichert et al., 1998).

\subsection{Microbial community analysis}

Microbial samples were collected from the three SBRs for microbial community analysis on $0 \mathrm{~d}, 15 \mathrm{~d}, 30 \mathrm{~d}$ and $45 \mathrm{~d}$. Total genomic DNA from the activated sludge samples was extracted using CTAB/SDS method. Sequencing libraries were generated using NEB Next®Ultra ${ }^{\text {TM }}$ DNA Library Prep Kit for Illumina (NEB, USA) following manufacturer's recommendations and index codes were added. The library quality was assessed on the Qubit@2.0 Fluorometer (Thermo Scientific) and Agilent Bioanalyzer 2100 system. DNA was amplified using the 341F/806R primer set (341F: 5'-CCTAYGGGRBGCASCAG-3', 806R: 5'-GGACTACNNGGGTATCTAAT-3'), which targets at the V3-V4 region of the bacterial 16S rDNA. Sequencing analysis 
was performed by UPARSE software package using the UPARSE-OTU and UPARSE-OTUref algorithms. Sequences with $\geq 97 \%$ similarity were assigned to the same OTUs.

\section{Results and Discussion}

\subsection{Effluent quality, sludge properties and PHA content in three SBRs}

In order to investigate the effects of OLR on PHA content and PHAaccumulating microorganisms selection, the three reactors (SBR-A, SBR-B and SBRC) with various OLRs $(1.2,2.4$, and $3.6 \mathrm{gCOD} / \mathrm{L} / \mathrm{d})$ were used. The sludge properties, substrate utilization, and PHA synthesis in the three reactors were monitored. The influent and effluent concentrations of COD, $\mathrm{NH}_{4}^{+}$, TN and TP in the experiments under various OLR are shown in Fig. 1. The influent $\mathrm{NH}_{4}{ }^{+}, \mathrm{TN}$ and $\mathrm{TP}$ in the three reactors were almost exhausted. The mean COD removal efficiency in the three reactors reached $91.8 \%, 96.2 \%$ and $93.2 \%$, respectively, demonstrating that rice winery wastewater could be easily degraded by the microorganisms in activated sludge.

The MLVSS and SVI values of the activated sludge in the three reactors are presented in Fig. 2. In SBR-A, the MLVSS decreased from $2750 \mathrm{mg} / \mathrm{L}$ to $920 \mathrm{mg} / \mathrm{L}$ while the SVI value increased from 77 to 173 , suggesting the deterioration of settling 
performance of activated sludge and the loss of mass sludge from the reactor (Fig. 2A). In SBR-B, the values of MLVSS and SVI increased from $2320 \mathrm{mg} / \mathrm{L}$ and 83 to $5230 \mathrm{mg} / \mathrm{L}$ and 169 , respectively, indicating that carbon source was sufficient for microbial growth and maintenance at OLR of $2.4 \mathrm{gCOD} / \mathrm{L} / \mathrm{d}$ (Fig. 2B). In SBR-C, the MLVSS decreased while the SVI increased sharply due to the filamentous sludge bulking, implying that a high OLR of $3.6 \mathrm{gCOD} / \mathrm{L} / \mathrm{d}$ and relatively low concentrations of nitrogen and phosphorus stimulated the growth of filamentous bacteria (Fig. 2C).

The contents of PHA in the three reactors in the experiments are illustrated in Fig. 3. The maximum PHA content in SBR-C (5.31-10.86\%) was higher than that in SBRA $(0.34-4.06 \%)$ and SBR-B (1.08-4.01\%) due to the high OLR $(3.6 \mathrm{gCOD} / \mathrm{L} / \mathrm{d})$ in the SBR-C. The maximum PHV contents in the three reactors increased from $0.32 \%, 1.25 \%$ and $0.99 \%$ to $2.70 \%, 2.36 \%$ and $1.50 \%$, respectively (Fig. 3E). The maximum PHB content in SBR-C was high (5.95\%-8.32\%) in the initial 20 days of experiments and then decreased to $3.81 \%$ because of the filamentous sludge bulking (Fig. 3C). However, fewer PHB $(<1.16 \%)$ was produced in the end of feast period in SBR-A and SBR-B. These results indicate that OLR had a significant effect on PHA production and rice winery wastewater was preferentially used for PHV synthesis. The high OLR in SBR-C and unbalanced $\mathrm{C} / \mathrm{N}$ ratio $(\mathrm{COD} / \mathrm{TN}=74.9)$ of the rice winery wastewater resulted in sludge bulking. Our previous study also show that a high $\mathrm{C} / \mathrm{N}$ ratio led to the outgrowth of filamentous microorganisms and a drop in sludge concentration (Fang et al., 2009). In addition, the increased $\mathrm{C} / \mathrm{N}$ ratio brought 
about a decrease in the observed coefficient of active-biomass yield $\left(Y_{\mathrm{obs}, \mathrm{BA}}\right)$ and an increase in the observed coefficient of PHA yield ( $\left.Y_{\text {obs,PHA }}\right)$ (Pokoj et al., 2019). However, Sepehri and Sarrafzadeh (2019) found that the minimum C/N ratio remarkably reduced the production of microbial metabolites and enhanced nitrification efficiency in the activated sludge process. Therefore, a proper OLR and $\mathrm{C} / \mathrm{N}$ ratio should be found to achieve microbial selection of PHA-accumulating microorganisms.

After 45-d operation, batch experiments were conducted to investigate the substrate consumption and PHA production in one cycle in the three reactors. As shown in Fig. 4, COD, TN and TP were quickly consumed by microorganisms in the three reactors. The PHA production in the batch experiments is listed in Table 2. The highest PHA yield of $0.23 \mathrm{gCOD} / \mathrm{gCOD}$ was achieved in SBR-B, which achieved the same level of PHB yield produced by Burkholderia cepacia using straw hydrolysates as substrate (0.25 gCOD/gCOD) (Cesario et al., 2014). The PHA yield was the lowest (0.115 gCOD/gCOD) in SBR-A, probably due to its low concentrations of substrate and MLVSS. At a high OLR of $3.6 \mathrm{gCOD} / \mathrm{L} / \mathrm{d}$, the PHA yield was also relatively low (0.152 $\mathrm{gCOD} / \mathrm{gCOD})$, indicating that the storage ability of the PHA-accumulating microorganisms was inhibited. This result is consistent with the results reported by Jia et al. (2013), who found that the PHA production was inhibited by a high OLR. Therefore, our results suggest that OLR of $2.4 \mathrm{gCOD} / \mathrm{L} / \mathrm{d}$ was favorable for PHA accumulation. 


\subsection{Shifts of microbial community at various OLR}

The high-throughput sequencing of the sludge samples from the three reactors in 45-d operation was performed. The taxonomic composition of bacterial populations in the three reactors was dominated by Proteobacteria, followed by Bacteroidetes, Verrucomicrobia, Patescibacteria, Acidobacteria, Chloroflexi, Firmicutes and Planctomycetes. Similarity analysis indicate that SBR-A and SBR-B were similar in terms of bacterial distribution after 45-d operation, while they were different from the SBR-C and the seeding sludge.

Genus level distribution of bacterial populations within three reactors is presented in Fig. 5. Numerous typical PHA-accumulating microorganisms were detected in the three reactors. Zoogloea, Rhodobacter and Rubrivivax present in all the three reactors were identified as PHA-accumulating microorganisms (Ciesielski et al., 2010, Jiang et al., 2011, Wieczorek et al., 1996). Besides, Leptothrix, Burkholderiaceae, Comamonas, Haliscomenobacter, Rhodobacteraceae, Amaricoccus and Plasticicumulans, reported as PHA-accumulating microorganisms in previous literature, were also detected in the three reactors (Dionisi et al., 2002,

Koller et al., 2010, Lemos et al., 2008, Obruca et al., 2018, Tamis et al., 2014).

However, their abundances were variable in the three reactors with various OLR.

The relative abundances of PHA-accumulating microorganisms within the three SBRs are summarized in Table 3. Zoogloea was the main PHA-accumulating 
microorganisms in all three reactors, while other PHA-accumulating microorganisms were relatively low in abundance. The total percentage of PHA-accumulating microorganisms within the three reactors reached $18.2 \%, 29.6 \%$ and $17.3 \%$, respectively, after 45-d operation. The highest abundance of PHA-accumulating microorganisms in SBR-B was consistent with the highest PHA yield $(0.23 \mathrm{~g} / \mathrm{g})$, implying that a moderate OLR (e.g., $2.4 \mathrm{gCOD} / \mathrm{L} / \mathrm{d}$ of this work) was favorable for PHA-accumulating microorganisms enrichment, while too low or too high OLR would lead to PHA-accumulating microorganisms out-competitive. For example, Sepehri and Sarrafzadeh (2018) found that the growth of nitrifying bacteria at a low OLR was greatly accelerated, which was not favorable for the selection of PHAaccumulating microorganisms.

\subsection{Modeling results of the batch and long-term experiments}

The sensitivity analysis of all parameters was conducted to identify the most determinant parameters on $S_{S}$ and $X_{P H A}$. The parameters $Y_{P H A}, Y_{H, S}, q_{P H A}$, and $m_{i, u_{H, S}}$ had a significant effect on $S_{S}$, while the parameters $Y_{P H A}, Y_{H, S}, Y_{P A B}, q_{P H A}, \operatorname{miu}_{P A B}$, and $K_{P H A}$ had a considerable influence on $X_{P H A}$. Therefore, seven parameters $\left(Y_{P H A}, Y_{P A B}\right.$, $Y_{H, S}, \mu_{H, S}, \mu_{P A B}, q_{P H A}$ and $\left.K_{P H A}\right)$ were chosen to be calibrated in this study.

The data from the batch experiments of SBR-B were chosen for parameter estimation. The experimental data and the results predicted with the calibrated model for SBR-B were compared. The good agreement between the experimental 
measurements and the model predictions of the substrate consumption process $\left(S_{S}\right)$ was observed. Moreover, the model results and measured data of PHA production and utilization process $\left(X_{P H A}\right)$ in the batch experiment also exhibited good consistency. The estimated average regression coefficient $\left(R^{2}\right)$ reached 0.89 and 0.83 , respectively.

In this modified model, the concentration change of $X_{P A B}$ and $X_{H}$ was an important indicator of PHA-accumulating microorganism selection process. In addition, the percentage of PHA-accumulating microorganisms in the total microorganisms $\left(f_{P A B}\right)$, which was equal to $X_{P A B}$ divided by the sum of $X_{P A B}$ and $X_{H}$, was also a significant factor affecting PHA production. Therefore, the modified model was further used to simulate the long-term microbial selection of PHA-accumulating microorganisms and performance of PHA production at OLR of $2.4 \mathrm{gCOD} / \mathrm{L} / \mathrm{d}$. As illustrated in Fig. 6, the concentrations of $X_{H}$ and $X_{P A B}$ in the modeling process gradually reached steady-state values of 4257 and $1844 \mathrm{mg} / \mathrm{L}$, respectively. Furthermore, the abundance of PHA-accumulating microorganisms in total microorganisms $\left(f_{P A B}\right)$ predicted by the model changed from $14.7 \%$ to $30.2 \%$, indicating the results of the microbial selection process of PHA-accumulating microorganisms.

The comparison between the model results and measured data at day 45 is listed in Table 4. The simulation and measured results of $f_{P A B}$ were $30.2 \%$ and $29.6 \%$, respectively. Moreover, the maximum $X_{P H A}$ reached 123.7 and $135.6 \mathrm{mgCOD} / \mathrm{L}$, respectively. The error percentages between model results and measured data of $f_{P A B}$ 
and the maximum $X_{P H A}$ were $2.0 \%$ and $8.7 \%$, respectively. The low error percentage and good consistency between the long-term simulation results and measured data indicate that the modified model could effectively describe the long-term PHAaccumulating microorganism selection process.

The estimated yield coefficient of PHA storage $\left(Y_{\mathrm{PHA}}\right)$ on rice winery wastewater was $0.41 \mathrm{mg} \mathrm{COD} / \mathrm{mg} \mathrm{COD}$ in our study, indicating that nearly $40 \%$ of consumed COD was transformed as PHA. However, the yield coefficient was lower than that (0.54) reported by Dias et al (2005). Different model structures, carbon sources, operation settings and microbial community might be responsible for the difference in yield coefficient. Although the $Y_{\mathrm{PHA}}$ on rice winery wastewater was not high as that on sodium acetate, the negative environmental value of rice winery wastewater and its need of treatment endow it a good substrate for PHA production. The values of some important parameter, such as OLR, $X_{H}, X_{P A B}$, and PHA yield, etc., are useful for further mathematical model improvement and PHA production with rice winery wastewater in full scale applications.

\subsection{Modeling the impact of OLR on microbial selection of PHA-accumulating microorganisms}

To further understand the effect of OLR on PHA-accumulating microorganisms, the above established model was used to simulate the variations of $X_{H}, X_{P A B}$ and maximum $X_{P H A}$ at various OLRs (ranging from 0.3 to $3.0 \mathrm{gCOD} / \mathrm{L} / \mathrm{d}$ ). Due to the 
filamentous bulking at high OLRs $(>3.0 \mathrm{gCOD} / \mathrm{L} / \mathrm{d})$, the results of high OLRs $(>3.0$ $\mathrm{gCOD} / \mathrm{L} / \mathrm{d}$ ) was not considered in this modified model. The identical initial microbial community data (Table 4) with various OLRs were used in the long-term modeling, and the results of $X_{H}, X_{P A B}$ and $\max X_{P H A}$ at various OLRs are summarized in Table 5. The modeling results show the modified ASM3 model successfully simulated the microbial selection process of PHA-accumulating microorganisms at low and moderate OLRs (i.e., $<2.4 \mathrm{gCOD} / \mathrm{L} / \mathrm{d})$ and moderate OLR $(2.4 \mathrm{gCOD} / \mathrm{L} / \mathrm{d})$ was beneficial for microbial selection and PHA production.

The OLR had an influence on microbial selection process of PHA-accumulating microorganisms through altering the feast/famine ratio and provided both the physiological and ecological selective pressures (Chen et al., 2017). Increased OLR leads to an extension of the feast phase and an increase in the F/F ratio, which would change the microbial community (Sepehri and Sarrafzadeh, 2019). Albuquerque et al. (2010) proposed that non-storing microorganisms might be able to endure these shorter famine phases, which was unbeneficial for the selection of PHA-accumulating microorganisms. The shorter famine phase might not ensure the decrease of growth cofactors to a point that limits microbial growth and favors PHA accumulation in the subsequent feast phase (Albuquerque et al., 2010). In addition, the high OLR with low $\mathrm{N}$ and $\mathrm{P}$ concentrations may cause filamentous bulking, which deteriorates the settling and PHA production of activated sludge and impairs the subsequent PHA recovery 
process. Therefore, the upper limit of the OLR provided by different substrates suitable for microbial selection and PHA production warrants further investigations.

\section{Conclusions}

The effects of OLR on PHA accumulation and PHA-accumulating microorganisms selection with rice winery wastewater as substrate were investigated in this study. The highest PHA yield of $0.23 \mathrm{gCOD} / \mathrm{gCOD}$ was achieved in SBR-B. Zoogloea was the most dominant PHA-accumulating microorganisms in three reactors and the highest content of PHA-accumulating microorganisms (29.6\%) was presented in SBR-B. The modified ASM3 model was established to evaluate and explore the effects of different OLR on the microbial selection and PHA accumulation. The experimental and model results implied that moderate OLR was beneficial for PHA accumulation and microbial selection of PHA-accumulating microorganisms.

\section{Acknowledgements}

This work was supported by the Fundamental Research Funds for the Central Universities (2017B13214), the National Natural Science Foundation of China (51878244, 51578210 and 51778301), and the Priority Academic Program Development of Jiangsu Higher Education Institutions (PAPD), China.

\section{Appendix A. Supplementary data}


E-Supplementary data for this work can be found in e-version of this paper online.

\section{References}

1. Albuquerque, M.G.E., Torres, C.A.V., Reis, M.A.M., 2010.

Polyhydroxyalkanoate (PHA) production by a mixed microbial culture using sugar molasses: Effect of the influent substrate concentration on culture selection. Water Res. 44(11), 3419-3433.

2. APHA., 2005. Standard Methods for the Examination of Water and Waste Water, 21st Edition. American Public Health Association, Washington DC.

3. Burniol-Figols, A., Varrone, C., Le, S.B., Daugaard, A.E., Skiadas, I.V., Gavala, H.N., 2018. Combined polyhydroxyalkanoates (PHA) and 1,3-propanediol production from crude glycerol: Selective conversion of volatile fatty acids into PHA by mixed microbial consortia. Water Res. 136, 180-191.

4. Campanari, S., e Silva, F.A., Bertin, L., Villano, M., Majone, M., 2014. Effect of the organic loading rate on the production of polyhydroxyalkanoates in a multistage process aimed at the valorization of olive oil mill wastewater. Int. J. Biol. Macromol. 71, 34-41.

5. Chen, Z., Guo, Z., Wen, Q., Huang, L., Bakke, R., Du, M., 2016. Modeling polyhydroxyalkanoate (PHA) production in a newly developed aerobic dynamic discharge (ADD) culture enrichment process. Chem. Eng. J. 298, 36-43. 
6. Chen, Z., Huang, L., Wen, Q., Zhang, H., Guo, Z., 2017. Effects of sludge retention time, carbon and initial biomass concentrations on selection process: From activated sludge to polyhydroxyalkanoate accumulating cultures. J. Environ. Sci. $52,76-84$.

7. Ciesielski, S., Pokoj, T., Klimiuk, E., 2010. Cultivation-dependent and independent characterization of microbial community producing polyhydroxyalkanoates from raw glycerol. J. Microbiol. Biotechn. 20(5), 853-861.

8. Coats, E.R., Watson, B.S., Brinkman, C.K., 2016. Polyhydroxyalkanoate synthesis by mixed microbial consortia cultured on fermented dairy manure: Effect of aeration on process rates/yields and the associated microbial ecology. Water Res. 106, 26-40.

9. Colombo, B., Pepe Sciarria, T., Reis, M., Scaglia, B., Adani, F., 2016. Polyhydroxyalkanoates (PHAs) production from fermented cheese whey by using a mixed microbial culture. Bioresour. Technol. 218, 692-699.

10. Cui, Y.-W., Shi, Y.-P., Gong, X.-Y., 2017. Effects of $\mathrm{C} / \mathrm{N}$ in the substrate on the simultaneous production of polyhydroxyalkanoates and extracellular polymeric substances by Haloferax mediterranei via kinetic model analysis. RSC Advances $7(31), 18953-18961$.

11. Das, M., Grover, A., 2018. Fermentation optimization and mathematical modeling of glycerol-based microbial poly(3-hydroxybutyrate) production. Process Biochem. 71, 1-11. 
12. Dias, J.M.L., Serafim, L.S., Lemos, P.C., Reis, M.A.M., Oliveira, R, 2005.

Mathematical modelling of a mixed culture cultivation process for the production of polyhydroxybutyrate. Biotechnol. Bioeng. 92, 209-222.

13. Dionisi, D., Levantesi, C., Renzi, V., Tandoi, V., Majone, M., 2002. PHA storage from several substrates by different morphological types in an anoxic/aerobic SBR. Water Sci. Technol. 46(1-2), 337-344.

14. Elsayed, N.S., Aboshanab, K.M., Yassien, M.A., Hassouna, N.A., 2018. Kinetic modeling, recovery, and molecular characterization of poly-beta-hydroxybutyrate polymer in Acinetobacter baumannii isolate P39. Bioprocess Biosyst. Eng. 41(12), $1779-1791$

15. Fang, F., Liu, X.W., Xu, J., Yu, H.Q., Li, Y.M., 2009. Formation of aerobic granules and their PHB production at various substrate and ammonium concentrations. Bioresource Technol. 100, 59-63.

16. Farghaly, A., Enitan, A.M., Kumari, S., Bux, F., Tawfik, A., 2016. Polyhydroxyalkanoates production from fermented paperboard mill wastewater using acetate-enriched bacteria. Clean Technol. Envir. 19(4), 935-947.

17. Fradinho, J.C., Domingos, J.M., Carvalho, G., Oehmen, A., Reis, M.A., 2013. Polyhydroxyalkanoates production by a mixed photosynthetic consortium of bacteria and algae. Bioresour. Technol. 132, 146-153.

18. Grazia, G.D., Quadri, L., Majone, M., Morgan-Sagastume, F., Werker, A., 2017. Influence of temperature on mixed microbial culture polyhydroxyalkanoate 
production while treating a starch industry wastewater. J. Environ. Chem. Eng. 5(5), 5067-5075.

19. Gujer, W., Henze, M., Mino, T., Loosdrecht, M.V., 1999. Activated Sludge Model No. 3. Water Sci. Technol. 39(1), 183-193.

20. Huang, L., Chen, Z., Wen, Q., Lee, D.J., 2017. Enhanced polyhydroxyalkanoate production by mixed microbial culture with extended cultivation strategy. Bioresour. Technol. 241, 802-811.

21. Jia, Q., Wang, H., Wang, X., 2013. Dynamic synthesis of polyhydroxyalkanoates by bacterial consortium from simulated excess sludge fermentation liquid. Bioresour. Technol. 140, 328-336.

22. Jiang, Y., Marang, L., Kleerebezem, R., Muyzer, G., van Loosdrecht, M.C.M., 2011. Effect of temperature and cycle length on microbial competition in PHBproducing sequencing batch reactor. Isme J. 5(5), 896-907.

23. Koller, M., Atlić, A., Dias, M., Reiterer, A., Braunegg, G., 2010. Microbial PHA Production from Waste Raw Materials. Plastics from Bacteria 14, 85-119.

24. Lemos, P.C., Levantesi, C., Serafim, L.S., Rossetti, S., Reis, M.A.M., Tandoi, V., 2008. Microbial characterisation of polyhydroxyalkanoates storing populations selected under different operating conditions using a cell-sorting RT-PCR approach. Appl. Microbiol. Biot. 78(2), 351-360.

25. Li, W.W., Yu, H.Q., 2011. From wastewater to bioenergy and biochemicals via two-stage bioconversion processes: A future paradigm. Biotech. Adv. 29, 972- 
982.

26. Li, Z.H., Ma, Z.B., Yu, H.Q., 2018. Respiration adaptation of activated sludge under dissolved oxygen and hypochlorite stressed conditions. Bioresour. Technol. $248,171-178$.

27. Luo, J., Wu, J., Zhang, Q., Feng, Q., Wu, L., Cao, J., Li, C., Fang, F., 2018. Efficient production of short-chain fatty acids from anaerobic fermentation of liquor wastewater and waste activated sludge by breaking the restrictions of low bioavailable substrates and microbial activity. Bioresour. Technol. 268, 549-557.

28. Marang, L., van Loosdrecht, M.C.M., Kleerebezem, R., 2016. Combining the enrichment and accumulation step in non-axenic PHA production: Cultivation of Plasticicumulans acidivorans at high volume exchange ratios. J. Biotechnol. 231, 260-267.

29. Morgan-Sagastume, F., 2016. Characterisation of open, mixed microbial cultures for polyhydroxyalkanoate (PHA) production. Rev. Environ. Sci. Bio. 15(4), 593625.

30. Mosse, K.P.M., Patti, A.F., Christen, E.W., Cavagnaro, T.R., 2011. Review: Winery wastewater quality and treatment options in Australia. Aust. J. of Grape Wine R. 17(2), 111-122.

31. Obruca, S., Sedlacek, P., Koller, M., Kucera, D., Pernicova, I., 2018. Involvement of polyhydroxyalkanoates in stress resistance of microbial cells: Biotechnological consequences and applications. Biotechnol. Adv. 36(3), 856-870. 
32. Oliveira, C.S., Silva, C.E., Carvalho, G., Reis, M.A., 2017. Strategies for efficiently selecting PHA producing mixed microbial cultures using complex feedstocks: Feast and famine regime and uncoupled carbon and nitrogen availabilities. N. Biotechnol. 37(Pt A), 69-79.

33. Pakalapati, H., Chang, C.K., Show, P.L., Arumugasamy, S.K., Lan, J.C., 2018. Development of polyhydroxyalkanoates production from waste feedstocks and applications. J. Biosci. Bioeng. 126(3), 282-292.

34. Pokoj, T., Klimiuk, E., Ciesielski, S., 2019. Interactive effect of crude glycerin concentration and $\mathrm{C}: \mathrm{N}$ ratio on polyhydroxyalkanoates accumulation by mixed microbial cultures modelled with Response Surface Methodology. Water Res 156, 434-444.

35. Reichert, P., Ruchti, J., Simon, W., 1998. Aquasim 2.0: Swiss Federal Institute for Environmental Science and Technology (EAWAG). CH-8600 Duebendorf Switzerland.

36. Rodriguez-Perez, S., Serrano, A., Pantion, A.A., Alonso-Farinas, B., 2018. Challenges of scaling-up PHA production from waste streams. A review. J. Environ. Manage. 205, 215-230.

37. Roncevic, Z.Z., Bajic, B.Z., Vucurovic, D.G., Dodic, S.N., Grahovac, J.A., Dodic, J.M., 2017. Xanthan production on wastewaters from wine industry. Hem. Ind. 71(2), 145-153.

38. Sepehri, A., Sarrafzadeh, M.-H., 2018. Effect of nitrifiers community on fouling 
mitigation and nitrification efficiency in a membrane bioreactor. Chem. Eng. Process. 128, 10-18.

39. Sepehri, A., Sarrafzadeh, M.-H., 2019. Activity enhancement of ammoniaoxidizing bacteria and nitrite-oxidizing bacteria in activated sludge process: metabolite reduction and $\mathrm{CO}_{2}$ mitigation intensification process. Appl. Water Sci. $9(5), 131$.

40. Tamis, J., Luzkov, K., Jiang, Y., van Loosdrecht, M.C.M., Kleerebezem, R., 2014. Enrichment of Plasticicumulans acidivorans at pilot-scale for PHA production on industrial wastewater. J. Biotechnol. 192, 161-169.

41. Teresa Cesario, M., Raposo, R.S., de Almeida, M.C.M.D., van Keulen, F., Ferreira, B.S., da Fonseca, M.M.R., 2014. Enhanced bioproduction of poly-3hydroxybutyrate from wheat straw lignocellulosic hydrolysates. New Biotechnol. 31(1), 104-113.

42. Uma, V., Gandhimathi, R., 2019. Organic removal and synthesis of biopolymer from synthetic oily bilge water using the novel mixed bacterial consortium.

Bioresour. Technol. 273, 169-176.

43. van Loosdrecht, M.C.M., Pot, M.A., Heijnen, J.J., 1997. Importance of bacterial storage polymers in bioprocesses. Water Sci. Technol. 35(1), 41-47.

44. Wang, J., Li, W.W., Yue, Z.B., Yu, H.Q., 2014. Cultivation of aerobic granules for polyhydroxybutyrate production from wastewater. Bioresour. Technol. 159, 442-445. 
45. Wen, Q., Ji, Y., Hao, Y., Huang, L., Chen, Z., Sposob, M., 2018. Effect of sodium chloride on polyhydroxyalkanoate production from food waste fermentation leachate under different organic loading rate. Bioresour. Technol. $267,133-140$.

46. Wieczorek, R., Steinbuchel, A., Schmidt, B., 1996. Occurrence of polyhydroxyalkanoic acid granule-associated proteins related to the Alcaligenes eutrophus H16 GA24 protein in other bacteria. Fems Microbiol. Lett. 135(1), 2330. 


\section{Figure Captions}

Fig. 1. Influent and effluent quality in the three reactors at various OLRs in the experiments: (A, D) $1.2 \mathrm{gCOD} / \mathrm{L} / \mathrm{d}$; (B, E) $2.4 \mathrm{gCOD} / \mathrm{L} / \mathrm{d}$; and (C, F) 3.6 $\mathrm{gCOD} / \mathrm{L} / \mathrm{d}$.

Fig. 2. Variations of MLVSS and SVI in the three reactors at various OLR during the experiments: (A) $1.2 \mathrm{gCOD} / \mathrm{L} / \mathrm{d}$; (B) $2.4 \mathrm{gCOD} / \mathrm{L} / \mathrm{d}$; and (C) $3.6 \mathrm{gCOD} / \mathrm{L} / \mathrm{d}$.

Fig. 3. PHA content in the sludge from the three reactors during the experiments: (A, C, E) total PHA, PHB, and PHV content at the end of feast phase; and (B, D, F) total PHA, PHB, and PHV content at the end of famine phase.

Fig. 4. Concentrations of $\mathrm{COD}, \mathrm{TN}$ and $\mathrm{TP}$ in batch experiments: (A, D) 1.2 $\mathrm{gCOD} / \mathrm{L} / \mathrm{d} ;(\mathrm{B}, \mathrm{E}) 2.4 \mathrm{gCOD} / \mathrm{L} / \mathrm{d}$; and (C, F) $3.6 \mathrm{gCOD} / \mathrm{L} / \mathrm{d}$.

Fig. 5. Genus level distribution of bacterial populations within three reactors: (A) 1.2 $\mathrm{gCOD} / \mathrm{L} / \mathrm{d}$; (B) $2.4 \mathrm{gCOD} / \mathrm{L} / \mathrm{d}$; and (C) $3.6 \mathrm{gCOD} / \mathrm{L} / \mathrm{d}$.

Fig. 6. Long-term simulated results of (A) $X_{H}, X_{P A B}$, and (B) $\max f_{P A B}$ at OLR of 2.4 gCOD/L/d using the modified ASM3 model. 
Table 1 Nomenclature of variables of modified PHA model used in this study

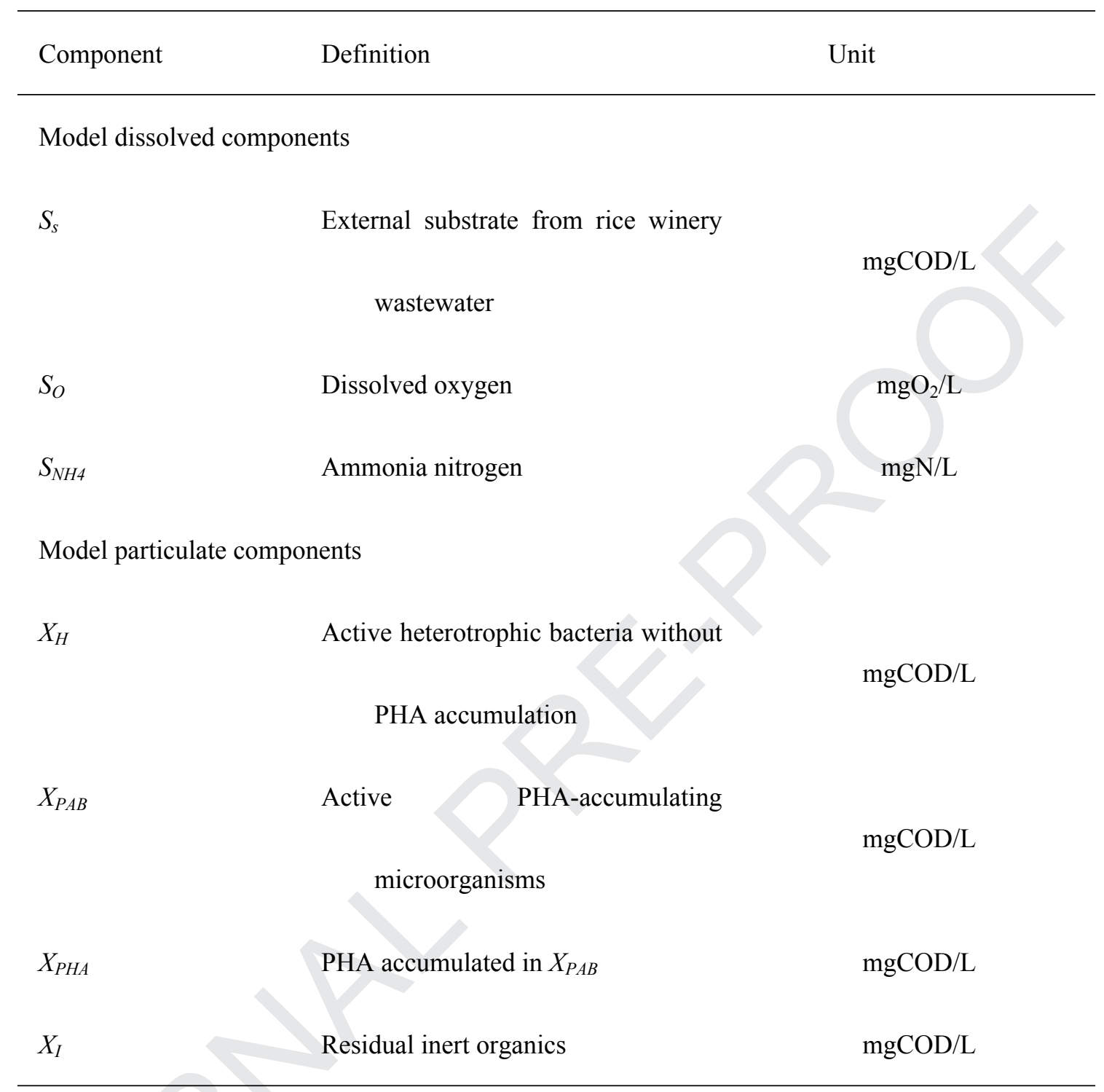


Table 2 Performance of PHA production by selected sludge at day 45 in batch experiments

\begin{tabular}{cccccc}
\hline SBR & MLVSS $(\mathrm{g} / \mathrm{L})$ & WV & OLR & Max PHA & PHA yield \\
& & $(\mathrm{L})$ & $(\mathrm{gCOD} / \mathrm{L} / \mathrm{d})$ & content $(\%)$ & $(\mathrm{g} / \mathrm{g})$ \\
\hline $\mathrm{A}$ & 0.92 & 3 & 1.2 & 3.76 & 0.12 \\
$\mathrm{~B}$ & 5.23 & 3 & 2.4 & 2.59 & 0.23 \\
$\mathrm{C}$ & 3.43 & 3 & 3.6 & 3.99 & 0.15 \\
\hline
\end{tabular}

WV: working volume (L)

PHA yield: g per PHA yield per g COD consumed $(\mathrm{g} / \mathrm{g})$ 
Table 3 Relative abundances of PHA-accumulating microorganisms within the three reactors in the experiments

\begin{tabular}{|c|c|c|c|c|c|c|c|c|c|}
\hline \multirow{2}{*}{$\begin{array}{l}\text { PHA producers \% } \\
\text { Genus }\end{array}$} & \multicolumn{3}{|c|}{ SBR-A } & \multicolumn{3}{|c|}{ SBR-B } & \multicolumn{3}{|c|}{ SBR-C } \\
\hline & $15 \mathrm{~d}$ & $30 \mathrm{~d}$ & $45 \mathrm{~d}$ & $15 \mathrm{~d}$ & $30 \mathrm{~d}$ & $45 \mathrm{~d}$ & $15 \mathrm{~d}$ & $30 \mathrm{~d}$ & $45 \mathrm{~d}$ \\
\hline Zoogloea ${ }^{\mathrm{a}}$ & 14.4 & 5.0 & 12.9 & 30.3 & 7.0 & 25.0 & 41.1 & 31.6 & 11.9 \\
\hline Rhodobacter ${ }^{\mathrm{a}}$ & 2.0 & 3.0 & 1.0 & 2.9 & 3.2 & 0.6 & 1.3 & 1.3 & 1.1 \\
\hline Rubrivivax ${ }^{\mathrm{a}}$ & 2.6 & 0.6 & 1.0 & 2.1 & 1.1 & 1.0 & 0.6 & 0.1 & 0.1 \\
\hline Leptothrix $x^{\mathrm{a}}$ & 0.9 & 0.5 & 0.2 & 1.0 & 0.2 & 0.1 & 2.5 & 2.0 & 0.1 \\
\hline$\alpha$-proteobacteria ${ }^{\mathrm{b}}$ & 2.5 & 0.9 & 0.4 & 1.5 & 1.5 & 0.4 & 0.3 & 0.7 & 0.3 \\
\hline Burkholderiaceae & 0.7 & 0.8 & 0.5 & 0.9 & 1.1 & 1.1 & 0.8 & 0.9 & 0.6 \\
\hline Comamonas $^{\mathrm{a}}$ & 1.1 & 1.0 & 0.9 & 0.7 & 0.7 & 0.3 & 0.5 & 0.2 & 0.1 \\
\hline Haliscomenobacter ${ }^{\mathrm{d}}$ & 0.8 & 0.4 & 0.8 & 0.5 & 0 & 0.2 & 0.3 & 1.5 & 1.0 \\
\hline Rhodobacteraceae & 0.5 & 0.8 & 0.3 & 1.0 & 1.5 & 0.4 & 0.9 & 0.7 & 0.4 \\
\hline Amaricoccus ${ }^{\mathrm{e}}$ & 0.1 & 0.1 & 0.2 & 0.2 & 0.2 & 0.3 & 0.1 & 0.9 & 1.7 \\
\hline Plasticicumulans $^{\mathrm{f}}$ & 0.3 & 0 & 0 & 0.2 & 0 & 0 & 0.9 & 1.3 & 0 \\
\hline Total & 25.9 & 13.1 & 18.2 & 41.3 & 16.5 & 29.6 & 49.3 & 41.2 & 17.3 \\
\hline
\end{tabular}

${ }^{a}$ Koller et al. (2010) ${ }^{b}$ Morgan-Sagastume (2016) ${ }^{c}$ Obruca et al. (2018) d Dionisi et al. (2002) ${ }^{\text {e }}$ Lemos et al. (2008) ${ }^{\mathrm{f}}$ Tamis et al. (2014) 
Table 4 Model conditions and results of the long-term microbial selection of PHA-accumulating microorganisms

\begin{tabular}{lccccc}
\hline & $X_{H}$ & $X_{P A B}$ & $X_{\text {total }}$ & $f_{P A B}$ & Max $X_{P H A}$ \\
& $(\mathrm{mg} / \mathrm{L})$ & $(\mathrm{mg} / \mathrm{L})$ & $(\mathrm{mg} / \mathrm{L})$ & $(\%)$ & $(\mathrm{mg} / \mathrm{L})$ \\
\hline Initial conditions & 2664 & 336 & 3000 & $11.2^{\mathrm{a}}$ & - \\
Measured results in batch & 3685 & 1549 & 5234 & $29.6^{\mathrm{a}}$ & 135.6 \\
experiment on day 45 & & & & & \\
Model results on day 45 & 4257 & 1844 & 6101 & $30.2^{\mathrm{b}}$ & 123.7 \\
\hline
\end{tabular}

$X_{\text {total }}$ : the sum of $X_{H}$ and $X_{P A B}$

$f_{P A B}$ : the percentage of $X_{P A B}$ in $X_{\text {total }}$

a, the value of $f_{P A B}$ determined by $16 \mathrm{~s}$ rDNA

b, the value of $f_{P A B}$ determined by model simulation 
Table 5 Model results of long-term microbial selection of PHA-accumulating microorganisms at various OLRs on Day 45

\begin{tabular}{llllll} 
OLR & $X_{H}$ & $X_{P A B}$ & $X_{\text {total }}$ & $f_{P A B}$ & Max $X_{P H A}$ \\
$(\mathrm{gCOD} / \mathrm{L} / \mathrm{d})$ & $(\mathrm{mg} / \mathrm{L})$ & $(\mathrm{mg} / \mathrm{L})$ & $(\mathrm{mg} / \mathrm{L})$ & $(\%)$ & $(\mathrm{mg} / \mathrm{L})$ \\
\hline 0.3 & 491 & 201 & 692 & 29.0 & 15.2 \\
0.6 & 987 & 408 & 1395 & 29.2 & 30.6 \\
1.8 & 3109 & 1325 & 4434 & 29.8 & 95.9 \\
2.4 & 4257 & 1844 & 6101 & 30.2 & 123.7 \\
3.0 & 5472 & 2411 & 7883 & 30.6 & 158.5 \\
\hline
\end{tabular}




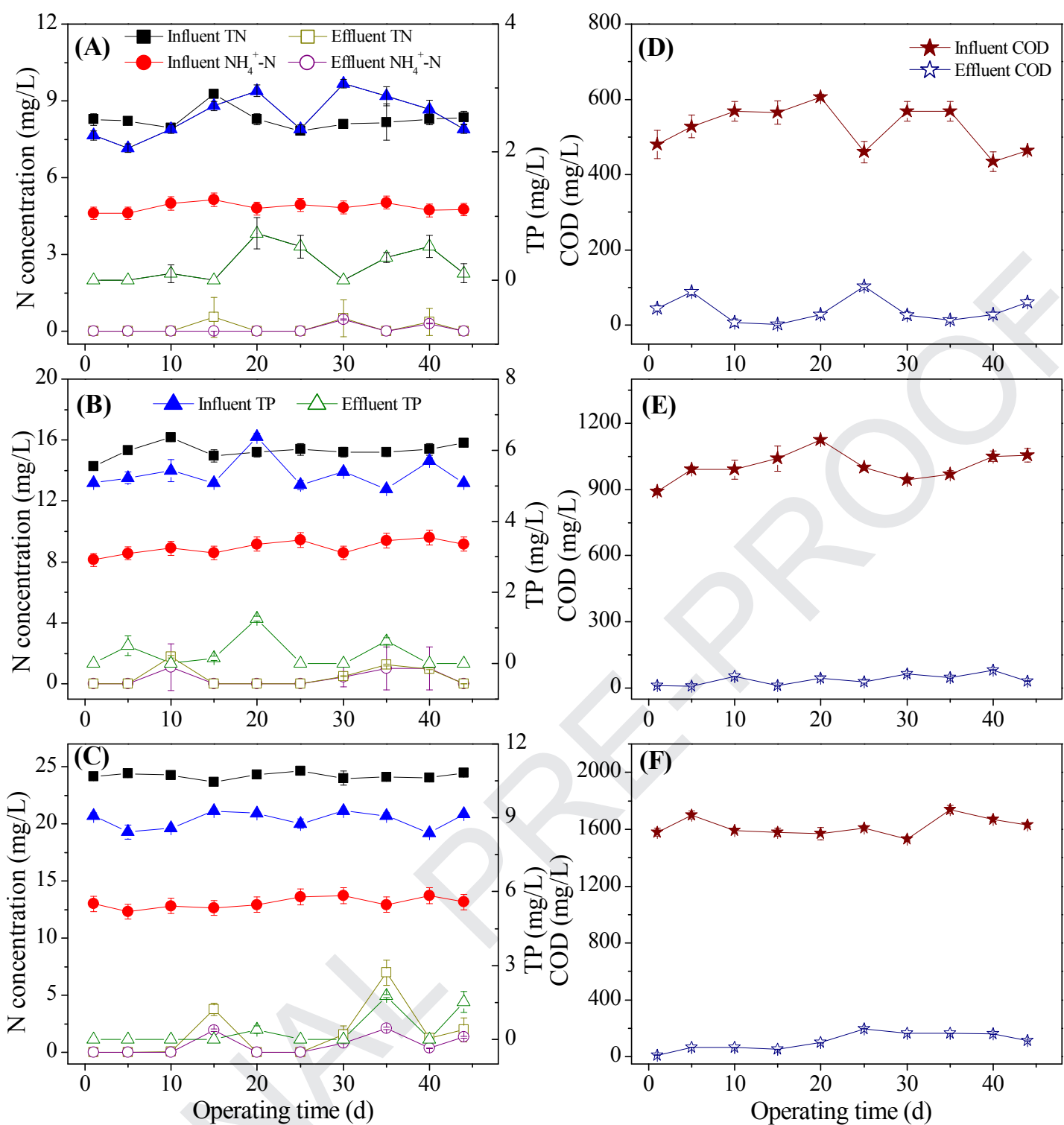

Fig. 1. Influent and effluent quality in the three reactors at different OLRs in the experiments: (A, D) $1.2 \mathrm{gCOD} / \mathrm{L} / \mathrm{d}$; (B, E) $2.4 \mathrm{gCOD} / \mathrm{L} / \mathrm{d}$; and (C, F) $3.6 \mathrm{gCOD} / \mathrm{L} / \mathrm{d}$. 

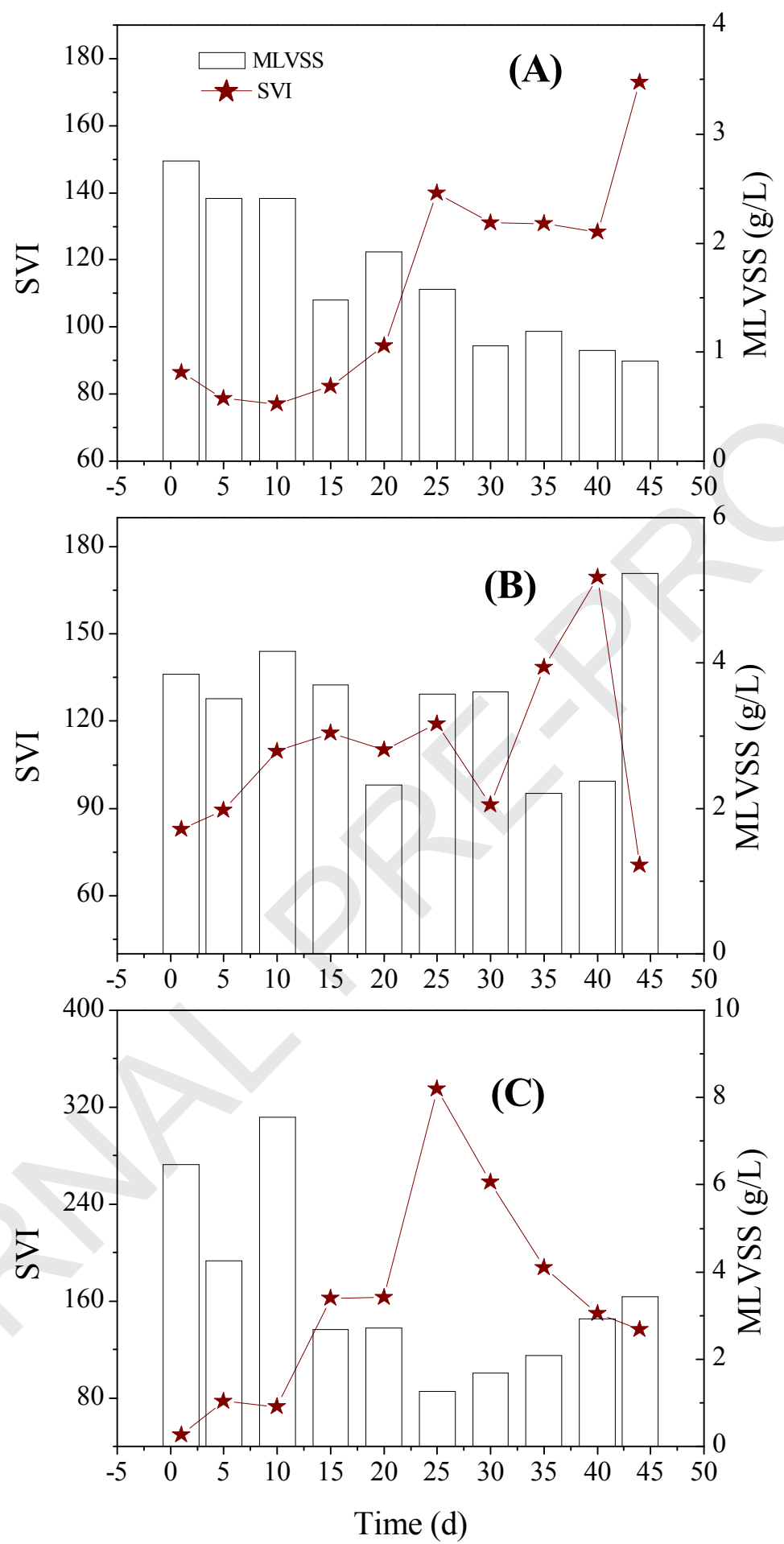

Fig. 2. Variations of MLVSS and SVI in the three reactors at different OLR during the experiments: (A) $1.2 \mathrm{gCOD} / \mathrm{L} / \mathrm{d}$; (B) $2.4 \mathrm{gCOD} / \mathrm{L} / \mathrm{d}$; and (C) $3.6 \mathrm{gCOD} / \mathrm{L} / \mathrm{d}$. 

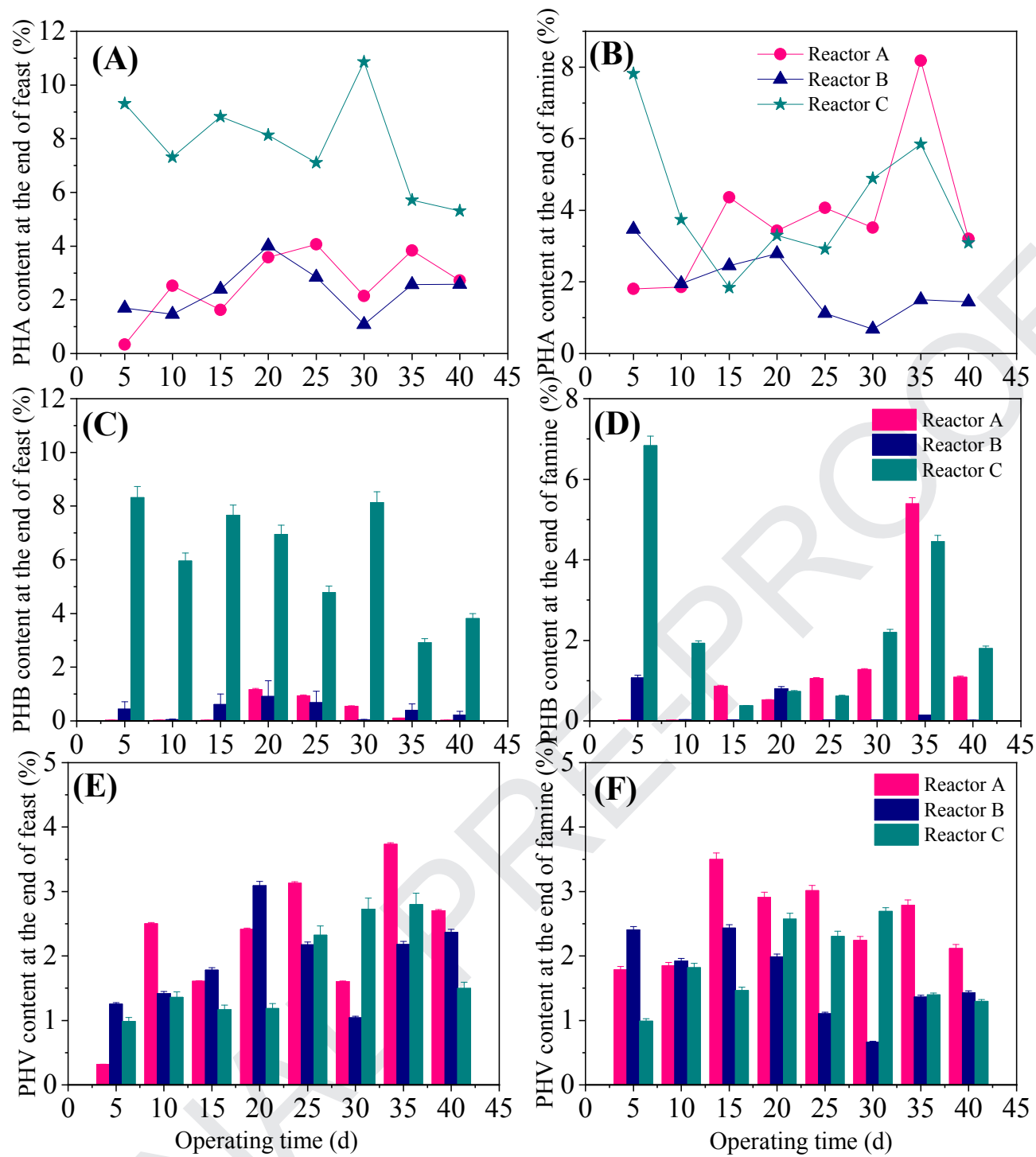

Fig. 3. PHA content in the sludge from the three reactors during the experiments: (A, C, E) total PHA, PHB, and PHV content at the end of feast phase; and (B, D, F) total PHA, PHB, and PHV content at the end of famine phase. 

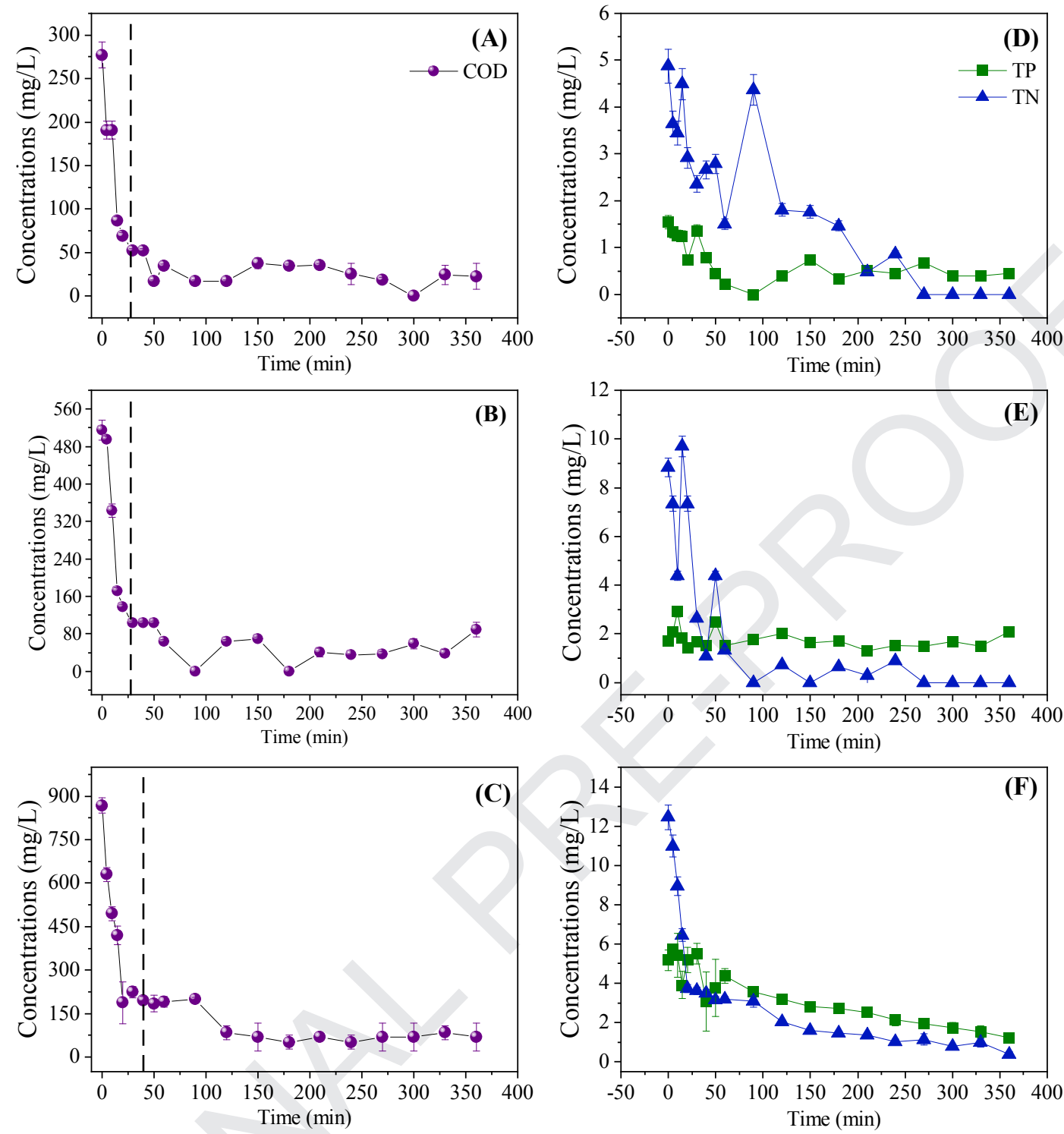

Fig. 4. Concentrations of $\mathrm{COD}, \mathrm{TN}$ and $\mathrm{TP}$ in batch experiments: (A, D) 1.2 $\mathrm{gCOD} / \mathrm{L} / \mathrm{d}$; (B, E) $2.4 \mathrm{gCOD} / \mathrm{L} / \mathrm{d}$; and (C, F) $3.6 \mathrm{gCOD} / \mathrm{L} / \mathrm{d}$. 


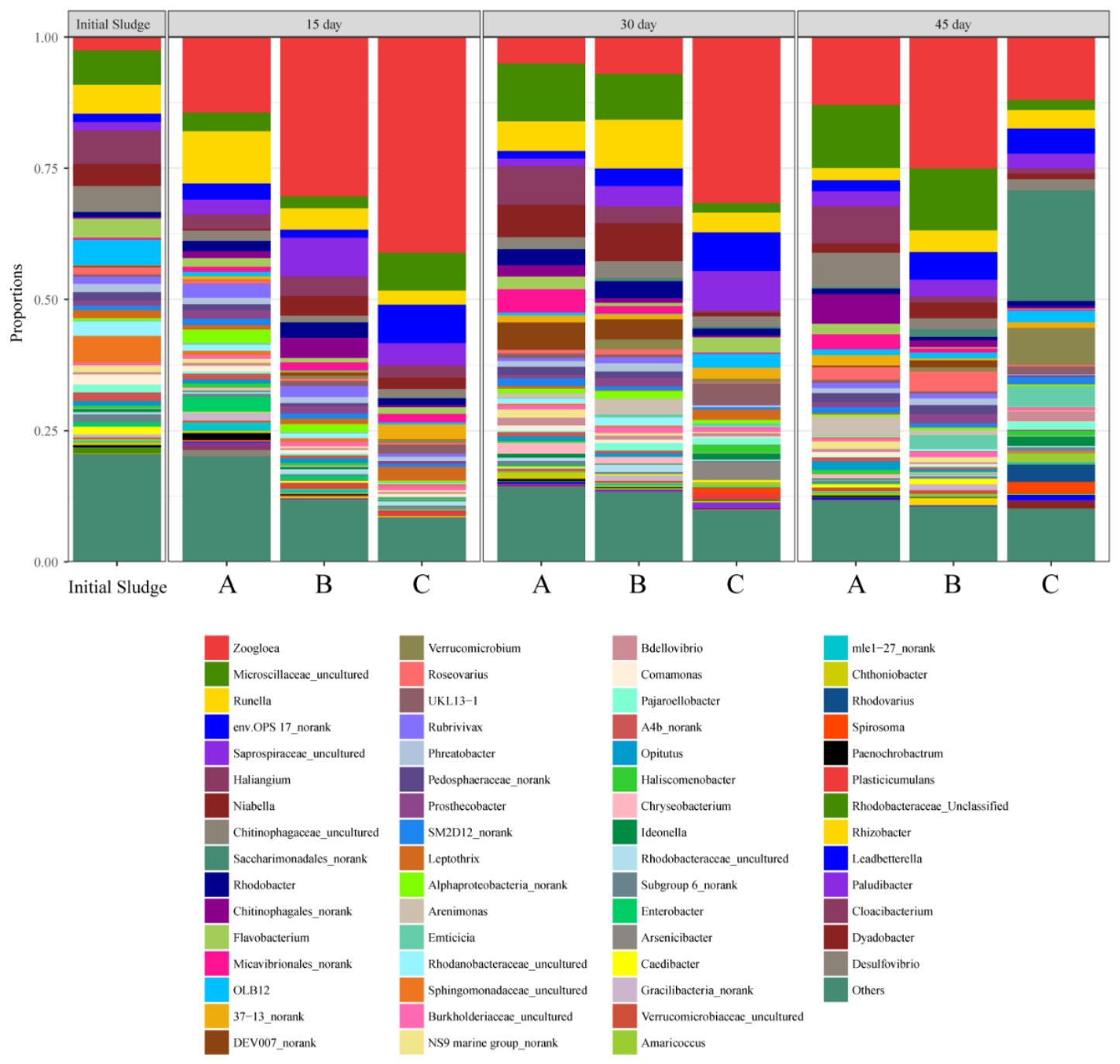

Fig. 5. Genus level distribution of bacterial populations within three reactors: (A) 1.2 $\mathrm{gCOD} / \mathrm{L} / \mathrm{d}$; (B) $2.4 \mathrm{gCOD} / \mathrm{L} / \mathrm{d}$; and (C) $3.6 \mathrm{gCOD} / \mathrm{L} / \mathrm{d}$. 

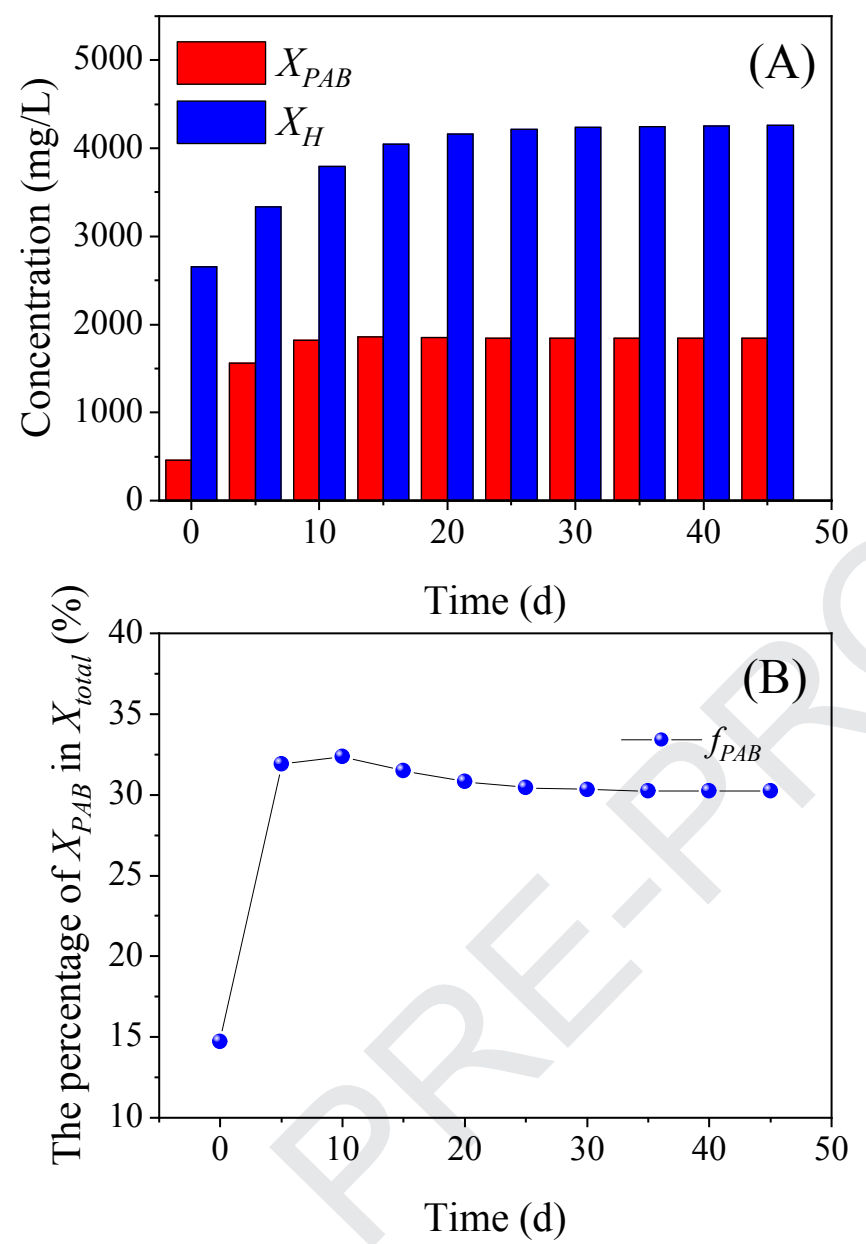

Fig. 6. Long-term simulated results of (A) $X_{H}, X_{P A B}$, and (B) $\max f_{P A B}$ at OLR of 2.4 $\mathrm{gCOD} / \mathrm{L} / \mathrm{d}$ using the modified ASM3 model. 


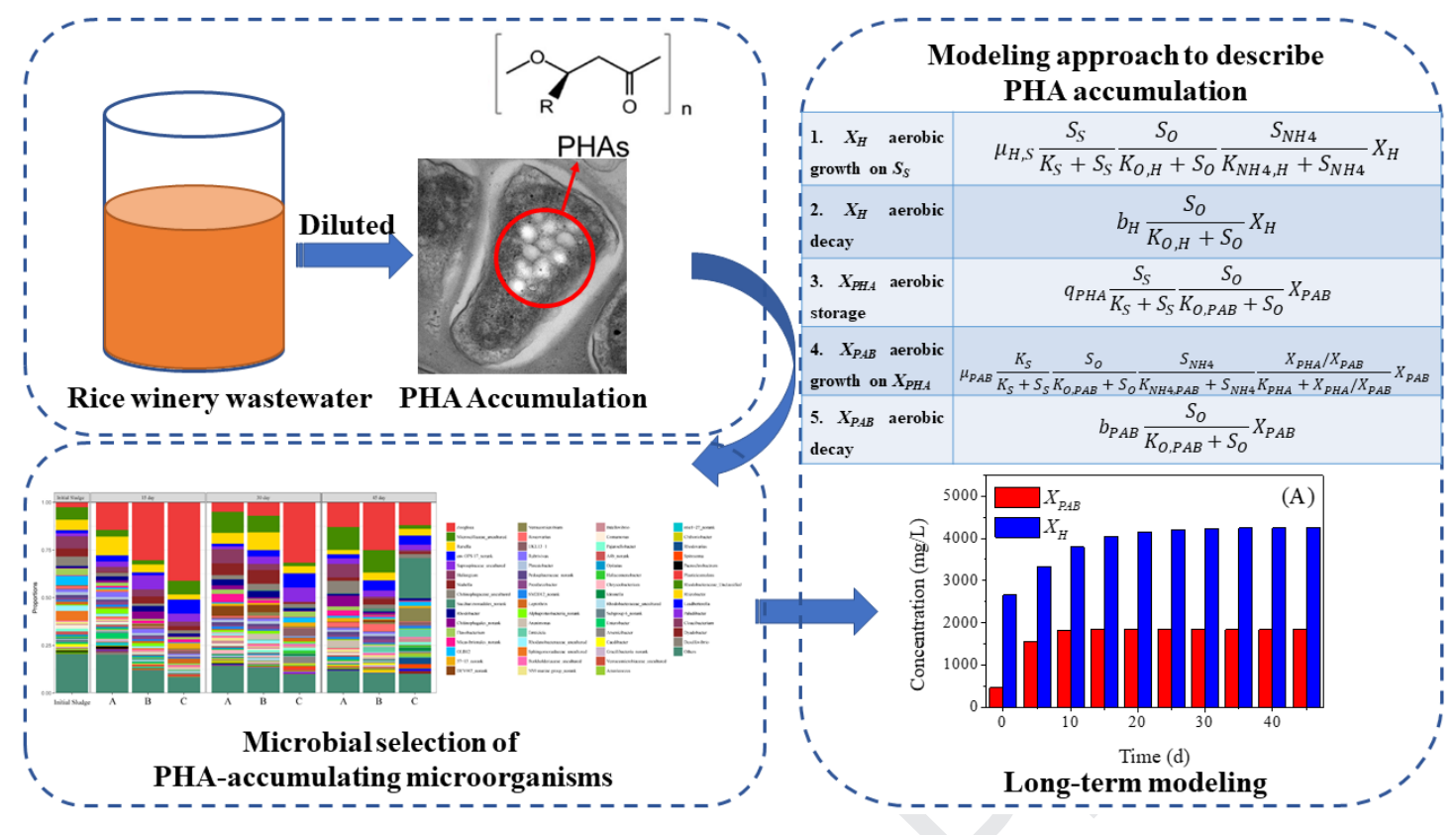




\section{Research Highlights}

- Rice winery wastewater was a proper substrate for PHA production by MMC

- Effects of OLR on the PHA microbial selection were investigated

- Moderate OLR was beneficial to microbial selection and PHA accumulation

- Zoogloea was the most dominant PHA-accumulating microbe in the reactors

- Modified ASM3 model was built to describe long-term PHA microbial selection 